\title{
Lessons from the Downfall of BSI in Singapore
}

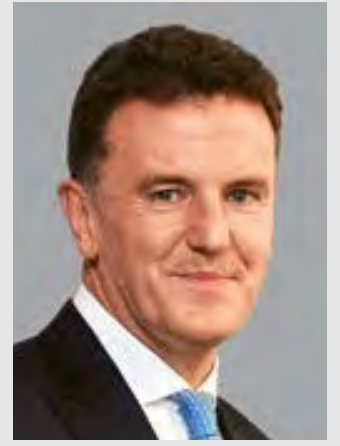

By Nick Pollard

"Growth for growth's sake" has long been a derided phrase in business circles. Though on one hand investors do love growth, on the other hand there are risks and real possibilities of public failure. Such seems to be the case at the Singapore branch of BSI SA, the Switzerland-based private bank that recently joined others in a string of high-profile connections to the 1MDB fiasco.

The last time an Asian banking scandal in Singapore grabbed global headlines was more than 20 years ago when Nicholas William "Nick" Leeson brought down Barings Plc, an episode that came to be seen as a classic case of financial risk management gone wrong.

While the details are still playing out in real time for BSI, there have been very public warning signals. In 2005, BSI Asia's then chief executive pronounced that it would become one of the top 10 private banks in Asia by tripling its regional funds under management by 2015. In 2009, BSI increased its headcount sevenfold in a matter of weeksnot unheard of in banking circles but notable for the sheer number of staff involved. Since 2014, ownership of the bank has changed hands from an Italian-based owner to a Brazilian-based owner to, now, a Swiss-based owner. This all took place amongst keen competition with the big global banks in the region-everyone wanted to tap into growing wealth in Indonesia, China, and India. Taken alone, each event was headline worthy; together, such events were red flags.

Then it all came crashing down. In May, Reuters reported that a Swiss regulator accused BSI of "routinely failing to carry out required background checks on large sums deposited." The bank's closure, as
KEEP GOING well as subsequent criminal investigations of key individuals, is now underway. Tax lawyer Philip Marcovici recently told the press, "Banking secrecy, not just in Switzerland, has created an atmosphere that has encouraged bad actions that are focused too much on what is good for the bank and not enough on what is good for society."

Were laws broken? Were there lapses in judgment? That's not for us to say, but there is a good deal of evidence that M\&A within the banking sectors-when different cultures and operating practices are combined-is a risky formula, one that has been well-documented by numerous banking scandals worldwide.

Financial services professionals widely acknowledge that codes of conduct are important drivers of reputational value. Here in Asia, the difference between the law and ethics is something we spend time talking about when running ethical decision-making workshops.

Decision making in business requires an integration of economic, legal, and moral inputs. Laws provide the basic framework within which economic activity is conducted. Ethics comes into play in order to make sound business decisions. Faulty decisions are often made because the ethical dimensions of the situation are not considered. In other words, just because you can do something doesn't mean you should.

The BSI scandal is a reminder of the importance of ethical standards and behavior, concepts that are embedded in our Code of Ethics and Standards of Professional Conduct.

In the end, another financial scandal has been added to the books, with new lessons to be learned. Asia-Pacific region at CFA Institute.

\section{Honoring Exceptional Professional Service}

CFA Institute will be honoring four individuals this year for their outstanding service to the investment profession. Each recipient has proven indispensable in promoting professionalism and ethical conduct and upholding the integrity of capital markets.

John Kay, FSIP, is a visiting professor at the London School of Economics and a fellow of St. John's College, Oxford. Previously, he was director of Saïd Business School, University of Oxford. Professor Kay is a fellow of the British Academy, the Royal Society of Edinburgh, and CFA
Society United Kingdom and chaired the review of equity markets and long-term decision making for the UK government. Professor Kay is chair of the Future of Finance Advisory Council of CFA Institute, a long-term global effort to shape a trustworthy, forward-thinking financial industry that better serves society. He is a director of several public companies, contributes a weekly column to the Financial Times, and is the author of several books. On 10 May 2016, Professor Kay received the Leadership in Professional Ethics and Standards of Investment Award, in honor of Daniel J. 